\title{
LA POLÍTICA EN LA CALLE: UTILIZACIÓN DEL ESPACIO PÚBLICO EN LA RIOJA DURANTE EL TRIENIO LIBERAL
}

\author{
Francisco Javier Díez Morrás \\ Universidad de La Rioja \\ francisco-javier.diez@unirioja.es
}

RESUMEN: El inicio de la época constitucional provocó en el país extraordinarias manifestaciones públicas de adhesión al nuevo sistema político. En La Rioja, especialmente en el Trienio Liberal, proliferaron los actos en favor de la Constitución de 1812, sus símbolos y sus instituciones. Para ello se hizo uso del espacio público por ser un ámbito idóneo para mostrar el apoyo a un nuevo tiempo. Los más importantes fueron organizados con motivo de la jura y proclamación constitucional, pero se sucedieron otros ante los atentados contra las lápidas de la Constitución, la apertura de las Cortes, o la presencia de un héroe del liberalismo en La Rioja como el general Riego. La respuesta de los absolutistas también se produjo en el ámbito público, lo que llevó a una guerra por los símbolos.

Palabras clave: liberalismo, constitucionalismo, absolutismo, espacio público, La Rioja.

\section{THE POLICY ON THE STREET: USE OF PUBLIC SPACE IN LA RIOJA DURING THE TRIENIO LIBERAL}

ABSTRACT: The beginning of the constitutional era in Spain provoked great public manifestations in favor of the new political system. In La Rioja, mainly in the Trienio Liberal, mass acts proliferated in support of the 1812 Constitution, its symbols and its institutions. For this reason, public spaces were taken as an ideal environment for the people to show their support for the upcoming changes. The most important events were organized on the occasion of the approval of the Constitution, but other acts took place to protest against the attacks on the tombstones of the Constitution, the opening of the Cortes, or 
the presence of heroes of liberalism in La Rioja, such as general Riego. The reply from the absolutists also happened in the public sphere, which led to a war for the symbols.

Keywords: Liberalism, constitutionalism, absolutism, public space, La Rioja.

Recibido: 4 de septiembre de 2019

Aceptado: 18 de octubre de 2019

\section{Introducción}

Tal y como destacó Fuentes Aragonés en uno de los estudios fundamentales sobre las fiestas políticas en el Trienio Liberal, el retorno al constitucionalismo echó a la calle a la ciudadanía desde el primer momento, protagonizando actos y manifestaciones públicas vinculadas al nuevo Estado liberal ${ }^{1}$. No fue algo realmente novedoso ni excepcional. Como ya había apuntado años antes Lécuyer, con anterioridad venía siendo utilizado el espacio público por los soberanos absolutos con una similar finalidad política y propagandística. Además, muchos de los rituales públicos desarrollados ahora por el liberalismo adaptaron los viejos esquemas, especialmente los más solemnes, que continuaron ordenándose según una misma articulación tripartita: iglesia, procesión y entretenimiento ${ }^{2}$.

En el presente trabajo nos vamos a centrar en los actos, fiestas y conmemoraciones de naturaleza política que durante el Trienio Liberal riojano se desarrollaron en una parte del espacio público, en concreto en las calles y plazas, pudiéndose observar las causas y motivos de su celebración, las formas que adoptaron y las gentes que lo protagonizaron. Otros ámbitos públicos en los que se produjeron manifestaciones políticas, como las tertulias, los cafés, la publicística o hasta las iglesias, se han incluido en otros trabajos. Es el caso de la Sociedad Patriótica de Logroño fundada en 1820, la cual celebró sus sesiones abiertas a toda la ciudadanía en el Café Nacional de la ciudad, organizando además un concurrido sermón en la colegiata de Santa María de la Redonda el 9 de julio con motivo de la instalación y apertura de las Cortes ${ }^{3}$.

La delimitación del espacio público como lugar de reunión, de encuentro o de manifestación de ideas debe partir de una previa determinación de lo

1. Fuentes Aragonés, J. F., "La fiesta revolucionaria en el trienio liberal (1820-1823)", Historia social 78 (2014), p. 45.

2. Lécuyer, M. C., "Fêtes civiques et libéralisme en Espagne (1812-1843)", Bulletin d'Histoire contemporaine de l'Espagne 30-31 (déc. 1999-jun. 2000), pp. 59-60.

3. Díez Morrás, F. J., "La antorcha de la libertad resplandece". La Sociedad Patriótica de Logroño y los inicios del liberalismo, Logroño, Instituto de Estudios Riojanos, 2016. El sermón está detallado en las pp. 107-115. 
público. Habermas destacó una acepción vinculada a la accesibilidad, planteando como primer ejemplo el espacio público físico formado por las calles, las plazas y determinados establecimientos. Entendía que también debían incluirse los edificios públicos ubicados en ellas, si bien en estos su 'publicidad' vendría dada especialmente por su integración en la Administración. Dentro de lo público, y más allá de los espacios, estaría también la opinión pública, de la cual el sujeto es su portador, lo que enlazaría con la prensa como elemento de atracción de dicha opinión, y evidentemente con la política ${ }^{4}$. Volviendo al espacio público, Fabra destacó la importancia que le otorgó el filósofo alemán, que lo consideró como el verdadero núcleo político de la Modernidad ${ }^{5}$, siendo además aquel donde "las personas privadas se reúnen en calidad de público" ${ }^{\text {. }}$.

Durante el antiguo régimen las variadas ceremonias celebradas en el espacio público habían sido un medio de comunicación fundamental con evidente carácter propagandístico, estando estrechamente relacionadas con el nacimiento de la opinión pública ${ }^{7}$. El primer liberalismo organizaría sus propios actos con similar intencionalidad, utilizando también para ello el mismo espacio y procurando transmitir su nuevo mensaje mediante la sustitución de los símbolos. Ahora, amparado en las nuevas libertades, y a pesar de que la Constitución de 1812 no recogió de manera expresa los derechos de asociación y reunión, haría un uso político con profusión y notable eficacia ${ }^{8}$. No obstante el artículo 371 contempló el derecho a escribir, imprimir y publicar ideas políticas sin censura, y en base a ese precepto se desarrolló la libertad de expresión en el ámbito público, pilar del régimen liberal ${ }^{9}$.

Como arriba se ha apuntado, el restablecimiento del constitucionalismo el 9 de marzo de 1820 con la jura de la Constitución por parte de Fernando VII, estuvo protagonizado en todo el país por un destacado ambiente festivo, el cual se prolongó durante días con las sucesivas juras y proclamaciones ${ }^{10}$. La Rioja no fue una excepción, y la celebración más institucional estuvo acompañada, y en ocasiones empujada, por espontáneas manifestaciones de júbilo de la ciudadanía. En las principales localidades riojanas las fiestas políticas y las solemnidades se verificaron especialmente en las calles, don-

4. Habermas, J., Historia y crítica de la opinión pública. La transformación estructural de la vida pública, Barcelona, Gustavo Gili, 1982, pp. 41-42.

5. Fabra, P., Habermas: lenguaje, razón y verdad. Los fundamentos del cognitivismo en Jürgen Habermas, Madrid, Marcial Pons, 2008.

6. Habermas J., Historia y crítica de la opinión pública..., p. 65.

7. López R. J., "Entre la tradición y la modernidad. Las ceremonias públicas gallegas en el reinado de Fernando VII", Espacio, Tiempo y Forma, Serie IV, 10 (1997), p. 377.

8. López González, J. L., El derecho de reunión y manifestación en el ordenamiento constitucional español, Madrid, Ministerio de Justicia e Interior, 1995, p. 19.

9. Fernández Sarasola, I., Los partidos políticos en el pensamiento español. De la Ilustración a nuestros días, Madrid, Marcial Pons, 2009, p. 60.

10. Fuentes Aragonés, J. F., "La fiesta revolucionaria...", pp. 45-53. 
de se ofrecieron desfiles militares, se lanzaron salvas de fusil, se colocaron iluminaciones extraordinarias, se quemaron fuegos artificiales y se organizaron largas sesiones de baile. Todas estuvieron acompañadas sin excepción por volteo de campanas y un habitual Te Deum de acción de gracias. El liberalismo español buscó la presencia de la Iglesia como legitimadora de la revolución, no hay que olvidar que consagró la confesionalidad del Estado a través del artículo 12 de la Constitución ${ }^{11}$. Además, para conseguir dar a los actos la solemnidad necesaria, estos fueron acompañados por ceremonias religiosas, siempre provistas de vistosas liturgias ${ }^{12}$. En esta región, como se podrá observar, desde las primeras semanas del Trienio hubo una significativa presencia y protagonismo de eclesiásticos en diversos actos públicos de exaltación constitucional. En definitiva, al igual que en el resto de España, en La Rioja el liberalismo salió a la calle, siendo no solo evidente sino muy notoria y explícita la alegría por el restablecimiento de la vigencia de la Constitución de $1812^{13}$.

Pero no fue únicamente la apertura de este nuevo período liberal la que llevó a la organización de actos públicos de celebración, pues a lo largo del Trienio se sucedieron de forma habitual en cuanto hubo un motivo real vinculado al nuevo sistema constitucional. Se produjo por tanto el nacimiento de nuevas festividades, como ya estudió Yamamichi para el caso de Barcelona. Un ejemplo lo vemos con motivo de la apertura de los distintos períodos de sesiones de Cortes $^{14}$. Porque el liberalismo no perdió la ocasión de propagar su ideario y celebrar hitos, triunfos y memoriales. La fundación de una sociedad patriótica, una declaración en las Cortes, victorias militares sobre los realistas, la reposición de la lápida de la Constitución ante su destrucción, o la llegada de algún personaje destacado de la política nacional, Ilevó a la organización de variados actos de adhesión. Los liberales convirtieron el espacio público en un escenario idóneo y buscado para hacer alarde y exhibición política y ganarse a la opinión pública, especialmente ante los ataques del absolutismo, siendo la calle un lugar privilegiado para la difusión y defensa del sistema liberal ${ }^{15}$. Además el liberalismo necesitaba unos nuevos símbolos para eclipsar los procedentes del absolutismo y que fuesen capaces de transmitir los valores liberales. De ahí que las Cortes aprobasen solemnizar pública y excepcionalmente los actos de jura y proclamación constitucional en las plazas mayores españolas, lo que Ilevó poco

11. La Parra, E., El primer liberalismo y la Iglesia. Las Cortes de Cádiz, Alicante, Instituto de Estudios Juan Gil-Albert, 1985.

12. Yamamichi, Y., "Fiestas y celebraciones cívico-religiosas en la Barcelona constitucional (1820-1823)", Espacio, Tiempo y Forma 15 (2002), p. 137.

13. Gil Novales, A., El Trienio liberal, Madrid, Siglo XXI, 1980, p. 7.

14. Yamamichi, Y., "Fiestas y celebraciones cívico-religiosas...", pp. 133-145.

15. Forcadell Álvarez, C., "Usos públicos de mitos, representaciones y símbolos en el primer liberalismo", Jerónimo Zurita 88 (2013), pp. 259-274. 
a poco a que también se fuesen realzando durante el Trienio Liberal otros hitos vinculados al nuevo sistema político ${ }^{16}$.

Ya en el primer y breve período constitucional riojano, abierto a finales de junio de 1813 y cerrado el 4 de mayo de 1814, las principales localidades celebraron en las calles la proclamación constitucional, en esta ocasión estrechamente unida a la salida de las tropas francesas. En Logroño, este nuevo tiempo tuvo su acto inaugural el 3 de julio de 1813, del cual dio noticia Baltasar Zapata, uno de los liberales más destacados del momento ${ }^{17}$. Según él, se efectuó en la plaza del Mercado y su entorno, la cual pasó a denominarse desde ese mismo momento plaza de la Constitución en virtud del decreto de 14 de agosto de $1812^{18}$. Se ofició en la colegiata de Santa María de la Redonda el inevitable Te Deum de acción de gracias, y se contó con la presencia de tropas españolas e inglesas que desfilaron y lanzaron salvas ${ }^{19}$. Sí consta en la documentación municipal calceatense la proclamación realizada en Santo Domingo de la Calzada el 11 de julio de 1813, excepcionalmente festiva y que duró varios días, en cuyas actas se señala que se organizó "no perdonando medio ni gasto sin embargo de lo extenuada que se halla esta ciudad"20.

La organización de fiestas, actos y celebraciones durante el primer liberalismo español ha sido abordada con detenimiento desde hace dos décadas tanto a nivel nacional como regional. No es posible hacer un recorrido exhaustivo, pero en el primer caso deben destacarse los trabajos ya citados de Fuentes Aragonés, Forcadell y Lécuyer, así como los de Roca Vernet ${ }^{21}$. Es especialmente relevante la investigación realizada por Sánchez Martín sobre Riego, en la que se incluyen las manifestaciones, honras y ceremonias que rodearon al héroe liberal y al liberalismo del Trienio ${ }^{22}$. En el ámbito local o regional se deben mencionar los trabajos de García León y Butrón Prida sobre Cádiz, ciudad principal del liberalismo español; o los de Arnabat y Yamamichi sobre Cataluña ${ }^{23}$. Final-

16. Morales Muñoz, M., "Símbolos y lugares de la memoria en torno a la Constitución de 1812", TSN. Transatlantic Studies Network: Revista de Estudios Internacionales 3 (2017), pp. 141-157.

17. Baltasar Zapata describió en un breve impreso en julio de 1813 el ambiente de la ciudad tras la salida de los franceses, Biblioteca de La Rioja (BR), Fondo Antiguo 002809(7).

18. Colección de los decretos y órdenes que han expedido las Cortes generales y extraordinarias, desde 24 de mayo de 1812 hasta 24 de febrero de 1813, tomo III, Cádiz, Imprenta Nacional, 1820, pp. 52-53.

19. BR, Fondo Antiguo 002809(7), fol. 3.

20. Archivo Municipal de Santo Domingo de la Calzada (AMSDC), Libro de acuerdos de 1813, sesión de 9 de julio.

21. Roca Vernet, J., "Fiestas cívicas en la revolución liberal: entusiasmo y popularidad del régimen", Historia Social 86 (2016), pp. 71-90.

22. Sánchez Martín, V., Rafael del Riego, símbolo de la revolución liberal, tesis doctoral, Universidad de Alicante, 2016.

23. García León, J. M., Cádiz en el Trienio Liberal (1820-1823), Cádiz, Fundación Municipal de Cultura, 1999; Butrón Prida, G., "La fiesta revolucionaria en el Cádiz constitucional", 
mente, en cuanto a La Rioja, desde hace unos años se ha despertado el interés por los comienzos del liberalismo en la región, apareciendo algunas publicaciones en las que se ha comenzado a destacar la existencia de fiestas políticas y actos públicos en ciudades como Logroño, Calahorra, Santo Domingo de la Calzada y $\mathrm{HarO}^{24}$.

Acerca de las fuentes utilizadas para la elaboración del presente trabajo, hay que señalar que se ha acudido principalmente a las actas municipales de las más importantes localidades riojanas, las cuales han ofrecido buena parte de la información al ser el espacio público urbano el principal escenario de celebración. Además, por lo general, fueron las autoridades municipales, acompañadas por ciudadanos liberales, las que promovieron u organizaron buena parte de los actos. Otros expedientes de naturaleza judicial y eclesiástica también han ofrecido referencias muy relevantes, al igual que las crónicas periodísticas. En este caso han sido de ámbito nacional, pues el único periódico regional del momento, El Patriota Riojano, no ofrece información sobre este tema.

\section{La jura y colocación de la lápida de la Constitución, la gran fiesta liberal}

Tras el pronunciamiento constitucional de Riego y un gran número de altos mandos militares en Andalucía el 1 de enero de 1820, a Fernando VII no le quedó más remedio que jurar la Constitución de 1812. Lo hizo motivado por las circunstancias y con repugnancia el 9 de marzo ${ }^{25}$. Sin embargo, los liberales celebraron con gran gozo el hecho $y$, al igual que en el bienio constitucional de 1812-1814, la jura de las autoridades y de la ciudadanía, y la inmediata y obli-

en Antiguo Régimen y liberalismo. Homenaje a Miguel Artola, vol. 3, Madrid, Alianza Editorial, Universidad Autónoma de Madrid, 1995, pp. 439-444; Butrón Prida, G., "Fiesta y revolución: las celebraciones políticas en el Cádiz liberal (1812-1837)", en Gil Novales, A. (coord.), La revolución liberal, Ediciones del Orto, 2001, pp. 159-178; Arnabat, R., "Propaganda antiliberal i lluita ideológica durant el Trieni Liberal a Catalunya (1820-1823)", Recerques: Història, economia i cultura 34 (1996), pp. 7-28; "La divulgación popular de la cultura liberal durante el Trienio: Cataluña, 1820-1823", Trienio: Ilustración y liberalismo 41 (2003), pp. 55-83; Yamamichi, Y., "Fiestas y celebraciones cívico-religiosas...", pp. 123-155.

24. En este caso deben consultarse los siguientes trabajos: Díez Morrás, F. J., "La antorcha de la libertad resplandece"...; Cañas Díez, S., Crisis del Antiguo Régimen y liberalismo en Calahorra (La Rioja) 1788-1840, tesis doctoral, Universidad de La Rioja, 2016; Díez Morrás, F. J., "Tiempo de cambios: Santo Domingo de la Calzada entre el Antiguo Régimen y el primer liberalismo", en Díez Morrás, F. J., Fandiño Pérez, R. G. y Sáez Miguel, P., Historia de la ciudad de Santo Domingo de la Calzada, Logroño, Instituto de Estudios Riojanos, 2010, pp. 387-504; Gómez Urdáñez, J. L., Bustos Torres, S. y Espinosa De Los Monteros, J. M., "El fin del Antiguo Régimen. Guerra, revolución y reacción en Haro", en Gómez Urdáñez, J. L. (dir.), Haro Histórico, Ayuntamiento de Haro, Universidad de La Rioja, 2017, disponible en http://www. gomezurdanez.com/haro/.

25. La Parra, E., Fernando VII. Un rey deseado y detestado, Barcelona, Tusquets, 2018, p. 399. 
gada colocación de la conocida como 'lápida de la Constitución' en las plazas donde se efectuaron las juras, se convirtió en la fiesta cívica por excelencia ${ }^{26}$. El acto se elevó ya en el primer período constitucional a la categoría de bautismo liberal; además, en la mayoría de las localidades del país, se trató de la más significativa manifestación pública del liberalismo. Siguiendo la terminología empleada por Lécuyer, esta fiesta entraría dentro de "les fêtes de souveraineté", por haber sido una de las establecidas de manera oficial por las Cortes, estando destinadas a consagrar la legitimidad del nuevo régimen liberal ante la opinión pública ${ }^{27}$.

Como señaló Fuentes Aragonés, durante los meses de marzo y abril de 1820, y con motivo de la proclamación de la Constitución, "España fue una fiesta"28, y La Rioja no fue una excepción. La primera localidad riojana que juró la Constitución en el Trienio fue Logroño. La proclamación y jura se realizó cuatro días después que el monarca, el 13 de marzo, y se describió brevemente en las actas municipales de esta manera:

... dichos Señores salieron de las referidas salas consistoriales acompañados del Señor Comandante del regimiento provincial de esta ciudad y de toda la oficialidad que se hallaba en ella, y reunidos se dirigieron a la plaza de la misma a publicar la Constitución política de la monarquía española que leí yo el escribano en alta y perceptibles voces. Cuyo acto, habiéndose celebrado y concluido con la solemnidad correspondiente, regresó dicho ilustre ayuntamiento a las citadas salas consistoriales ${ }^{29}$.

El ambiente de la ciudad no venía siendo muy favorable debido a los obstáculos puestos por el corregidor absolutista Luis de Lemos para realizar el tránsito al régimen constitucional, de hecho la jura de la Constitución se produjo siete días antes de la elección del primer ayuntamiento constitucional ${ }^{30}$. Pero a pesar de ello, o debido precisamente a esas reticencias de los sectores absolutistas, se verificó con gran solemnidad, acordándose dar tras el acto una gratificación a la tropa que había asistido ${ }^{31}$.

26. Fuentes Aragonés, J. F., "La fiesta revolucionaria...", p. 58.

27. Lécuyer, M. C., "Fêtes civiques et libéralisme...", p. 55.

28. Fuentes Aragonés, J. F., "La fiesta revolucionaria...", p. 45.

29. Archivo Municipal de Logroño (AML), Libro de acuerdos de 1819-1820, sesión de 13 de marzo de 1820.

30. Todas las circunstancias, el contexto y los problemas previos se han abordado en Díez Morrás, F. J., "La antorcha de la libertad resplandece"..., pp. 37-54.

31. Lo mandaba la Orden de 18 de marzo de 1812 por la que se mandaba dar una gratificación a las tropas el día en el que se publicase la Constitución de la Monarquía, Colección de los decretos y órdenes que han expedido las Cortes generales y extraordinarias, desde 24 de septiembre de 1811 hasta 24 de mayo de 1812, tomo II, Cádiz, Imprenta Nacional, 1820, p. 176. 
En Santo Domingo de la Calzada, capital del corregimiento de Rioja que abarcaba la mayor parte de La Rioja Alta, la elección del ayuntamiento constitucional se realizó antes de la jura, el 17 de marzo, el cual quedó formado por un alcalde, seis regidores y un procurador síndico. Se hizo de acuerdo con el real decreto de 12 de junio de $1812^{32}$. Realizada la elección, inmediatamente y ese mismo día se procedió a proclamar y jurar la Constitución de 1812. Lo hizo en primer lugar el alcalde, Miguel Antonio de Tejada y Otálora, siendo el maestro de ceremonias el corregidor saliente. Fue el alcalde el que, a continuación, tomó el juramento a los regidores y procurador síndico, que tomaron también posesión. Se trataba de un acto con gran importancia y simbolismo, pues ante una multitud se acataba la norma suprema, obligando con ello a toda la población a hacer lo propio. Este acto fue solemnizado como correspondía y a las tres de la tarde el alcalde y su ayuntamiento, acompañados por el corregidor cesante, el cabildo catedralicio, la congregación de capellanes, el subdelegado de rentas reales, el guardián del convento de San Francisco, y el pueblo asistente, salieron hacia la plaza Mayor en procesión situándose las autoridades en un tablado. Un niño vestido de ángel trajo en una bandeja de plata un ejemplar de la Constitución que entregó al escribano y este al regidor Garrido, que la leyó en voz alta, así como el decreto de la regencia sobre su observación. El acto lo dio por finalizado el alcalde "entre la aclamación del público y repetidos fuegos que dispararon, diciendo viva el rey don Fernando Séptimo, viva la Constitución, viva nuestro pueblo fiel". Se vivió entonces el mismo ambiente de fiesta que en julio de 1813, cuando se juró por primera vez la Constitución en la ciudad ${ }^{33}$.

Por su parte, el cabildo catedralicio se sumó al ambiente de júbilo con la organización de una misa solemne el 25 de marzo como acción de gracias por la publicación de la Constitución "concluida la cual se ha de prestar el juramento en los términos que previene la misma", prosiguiendo un Te Deum ${ }^{34}$. La Constitución se leyó en la misa antes del ofertorio, y el sacerdote Francisco García del Valle hizo una exhortación del texto. Finalizada la función religiosa, el alcalde tomó juramento a los eclesiásticos ${ }^{35}$, con lo que la iglesia local se unía de forma aparentemente entusiasta al constitucionalismo por estar avalada su jura con la previa aceptación de Fernando VII.

La importante villa de Haro, integrada entonces en el corregimiento calceatense, también proclamó solemnemente la Constitución el lunes 27 de marzo en la plaza Mayor. Se adornó la fachada del ayuntamiento y sobre un tablado presidido por un retrato del rey se celebró el acto "a la vista de un inmenso gentío expectante de la

32. AMSDC, Libro de acuerdos de 1820, sesión de 17 de marzo.

33. AMSDC, Libro de acuerdos de 1820, sesión de 19 de marzo.

34. AMSDC, Libro de acuerdos de 1820, sesión de 21 de marzo.

35. AMSDC, Libro de Acuerdos de 1820, sesión de 25 de marzo. 
ceremonia". Se leyó la Constitución y el alcalde constitucional Patricio Ponce de León, que había sido elegido el 20 de marzo, dijo que había llegado el feliz día en el que el rey había jurado la Constitución, instando a todos los "ciudadanos" a someterse a las autoridades constituidas, obedecer las leyes, venerar la religión, amar al rey y ser fieles a la Constitución. Tras ello se celebró el preceptivo Te Deum ${ }^{36}$.

No fue muy diferente en Calahorra, la segunda ciudad riojana en población y sede episcopal. En esta se ordenó que la jura y proclamación fuese el 18 de marzo, instalándose también un tablado para el acto. El alcalde constitucional fue Gaspar de Miranda ${ }^{37}$. En este caso hubo algún conflicto en la catedral ante la negativa de algunos eclesiásticos a presidir el acto que se debía realizar en dicho templo por no ser un asunto de su estricta competencia ${ }^{38}$.

Por tanto, se observa que en las principales localidades riojanas las juras se hicieron en el espacio público, lugar en el que debía colocarse inmediatamente la lápida de la Constitución, estando acompañadas por otros actos de naturaleza festiva y popular no muy diferentes a los organizados con anterioridad al liberalismo. En todos ellos se contó con una asistencia multitudinaria y heterogénea, siendo organizados por las autoridades municipales. No constan altercados en esos momentos, por lo que se debe entender que los contrarios al sistema constitucional se mantuvieron al margen, aunque es muy probable que mezclados entre la ciudadanía.

En algunas localidades la ceremonia de jura y colocación de la lápida tuvo ciertas peculiaridades, no tanto por la actitud de los regidores, sino por el protagonismo que adquirieron algunos elementos liberales. Fue el caso de Aldeanueva de Ebro, donde el párroco y cura beneficiado de la villa, Román de Lerena, un destacado liberal natural de San Millán de la Cogolla, utilizó las andas procesionales del patrono de la localidad, San Bartolomé, para sacar en procesión la lápida de la Constitución previamente a ser colocada en la plaza principal de la localidad. Unos meses después Lerena saldría a recibir a caballo al general Riego a su paso por la villa en dirección a Tudela. Esas exhibiciones liberales serían tenidas en cuenta a partir de 1823, una vez derribado el sistema constitucional, por las nuevas autoridades tanto civiles como eclesiásticas, las cuales le harían pagar esas veleidades políticas con el presidio y el confinamiento ${ }^{39}$.

También en Navarrete el protagonismo de la jura estuvo en manos eclesiásticas. En este caso fue Antonio de Mendizábal y Llorente, cura beneficiado de la

36. La proclamación de la Constitución en Haro se recoge en: Archivo Municipal de Haro $(\mathrm{AMH})$, Libro de decretos del ayuntamiento constitucional de 1820, Publicación y Jura de la Constitución Política de la Monarquía Española.

37. Cañas Díez, S., Crisis del Antiguo Régimen..., p. 458.

38. Ibídem, pp. 478 y ss.

39. Díez Morrás, F. J., "Román de Lerena, el cura que salió a recibir a Riego", Piedra de Rayo 52 (2018), pp. 60-69. 
localidad, quien ofreció una proclama pública de gran éxito. El Diario Mercantil de Cádiz la calificó como "excelente discurso" ${ }^{40}$. En él insistió en su defensa de la Constitución, y especialmente en la protección expresa que esta hacía de la religión en su artículo 12. Su intención era clara, pues uno de los argumentos de los anticonstitucionales era la supuesta oposición del sistema constitucional a la religión. En su discurso, siguiendo con ello la trayectoria de su tío, el sacerdote y antiguo afrancesado Juan Antonio Llorente, alabó con firmeza la supresión de la Inquisición, establecida según él por hombres ignorantes, y la atribución a los obispos de algunas de las competencias de aquel tribunal ${ }^{41}$.

\section{La respuesta absolutista}

El ya indicado decreto de las Cortes de 14 de agosto de 1812 ordenó que la plaza principal de las localidades en las que se jurase y promulgase el texto constitucional pasase a ser denominada como 'plaza de la Constitución', y así se hizo en La Rioja. Tal y como decía la norma, su intención era "fijar por todos los medios posibles en la memoria de los españoles la feliz época de la promulgación de la Constitución". El decreto establecía además "que se exprese así en una lápida erigida en la misma"42.

Como consecuencia de lo anterior, las lápidas de la Constitución se convirtieron en todo el país en un símbolo de enorme fuerza ideológica. Como señaló Reyero, "la importancia que los liberales concedieron al ritual de colocación de lápidas constitucionales permite hablar de un verdadero culto a la Constitución a través de ellas" ${ }^{\prime 43}$. La lápida pasó a ser el símbolo más visible y evidente de que la ciudadanía se encontraba ante un nuevo tiempo, por lo que los realistas la utilizaron precisamente en signo contrario, es decir, como objeto en el que mostrar su oposición. En La Rioja fue la lápida de la ciudad de Logroño la que con mayor virulencia experimento esos ataques, agresiones y destrozos. Tras la celebración de determinados actos liberales, los absolutistas expresaron su ira ensañándose con ella.

La primera acción de ataque de los absolutistas se produjo el 18 de marzo y está relacionada con la elección del ayuntamiento constitucional, pues ese día se eligió a los electores que estaban destinados a designar a los dos alcaldes y al resto de miembros del nuevo ayuntamiento. Parece ser que dos granaderos destrozaron la tabla provisional que había sido colocada el día 13 con la jura ${ }^{44}$.

40. Diario Mercantil de Cádiz 1416, lunes 19 de junio de 1820, pp. 2-4.

41. Ibídem.

42. Colección de los decretos y órdenes..., Tomo III, pp. 56-57.

43. Reyero Hermosilla, C., Alegoría, nación y libertad. El Olimpo constitucional de 1812, Madrid, Siglo XXI, 2010, p. 195.

44. AML, Libro de acuerdos de 1819-1820, sesión de 19 de marzo de 1820. 
El ayuntamiento provisional, pues el definitivo sería elegido el día 20, reunido urgentemente el día 19, mandó colocar cuatro nuevas tablas. Se hicieron pesquisas, pero solo se pudo determinar que habían sido dos granaderos del Regimiento Provincial, sin haberse podido dar con su identidad. Varios liberales que días después fundarían la Sociedad Patriótica de Logroño, instaron al juez a que se persiguiese a sus autores ${ }^{45}$.

Unas semanas después, el 2 de abril, se volvió a atentar contra una de las tablas situada en una de la torres de la colegiata de Santa María de la Redonda. Ese día por la noche fue detenido Benito Catalina por dos liberales, León de Orbe y Bernabé Martínez, que le acusaron de haber pegado un tiro a dicha placa de la Constitución ${ }^{46}$. Orbe y Martínez ejecutaron la detención unilateralmente y con cierta violencia, pues los autos judiciales de la causa indican que "don León Orbe y don Bernabé Martínez de su propia autoridad y bajo un celo aparente o indirecto por la Constitución han allanado la casa posada de Don Benito Catalina arrojándolo al suelo, arrancándolo a la fuerza de aquella con amenazas de muerte, colocándolo en la cárcel" ${ }^{\prime 47}$.

Todo parece indicar que Catalina fue pillado in fraganti y ambos, sin duda enfadados por este nuevo atentado contra el símbolo constitucional de la ciudad, lo arrancaron de manera violenta de su hospedaje y lo enviaron a presidio. Catalina fue exculpado por Luis de Lemos, antiguo corregidor absolutista y ahora juez de primera instancia provisional señalando "que don Benito Catalina no dirigió dicho tiro con otra intención que la de descargar la escopeta a dicha pared para no ofender con los perdigones a persona alguna, sin que la mancha del rótulo citado procediese tampoco del tiro sino de la equivocación del pintor". Concluyó el juez indicando que los desperfectos de la placa se debían en realidad a la poca destreza del pintor que la había hecho. Un argumento realmente insostenible. Además Orbe y Martínez fueron condenados, pues la sentencia declaró que ambos se habían excedido al trasladar a Catalina a prisión utilizando pistolas y alterando la tranquilidad pública. Se les condenó a la pena de destierro durante seis años ${ }^{48}$.

Este hecho y la sentencia enfadaron a los liberales, que el día 17 de abril, tras la fundación de la Sociedad Patriótica el 12 de abril, enviaron en nombre de esta un escrito al ayuntamiento solicitando la inmediata colocación de la lápida de la plaza de la Constitución ${ }^{49}$. Cinco días después, el 22 de abril, el

45. Archivo Histórico Provincial de La Rioja (AHPLR), Judicial, 211/7, Causa formada del real oficio de Justicia en averiguación del autor o autores que han quitado de mano airada de la Plaza de esta ciudad la tabla que provisionalmente se había colocado con la inscripción de Plaza de la Constitución, s. p.

46. AHPLR, Judicial, 193/12.

47. Ibídem.

48. Ibídem.

49. AML, Libro de acuerdos de 1819-1820, sesión de 20 de abril de 1820. 
Marqués de San Nicolás, alcalde primero de la ciudad, y el procurador síndico Nicolás Peral, se encargaron de comprar una nueva lápida ${ }^{50}$. El 30 de mayo, festividad de la onomástica del rey, se instalaron dos lápidas, una en cada torre de la colegiata de Santa María de la Redonda. En principio se pensó hacerlo de forma discreta, sin embargo los liberales logroñeses decidieron hacerlo públicamente acudiendo a la plaza la corporación en pleno, el clero, el pueblo y el Regimiento Provincial, que lanzó varias salvas. Hubo también fuegos artificiales y música a cargo de la orquesta de la Academia de Bellas Artes de la ciudad ${ }^{51}$. La solemnidad y publicidad del acto tuvo una clara intención propagandística y fue una reafirmación constitucional.

En otras localidades riojanas también fue atacada la lápida de la Constitución, si bien no ha sido posible encontrar una relación directa con hechos o celebraciones vinculadas al liberalismo. En particular, el 22 de abril de 1821, fue ensuciada con barro en Fuenmayor la lápida ubicada en su plaza Mayor, aunque no se dio con su autor. Hay que señalar que esos días salieron tropas de distintas poblaciones riojanas, y especialmente de Logroño, en dirección a la villa alavesa de Salvatierra para combatir la más importante rebelión anticonstitucional ocurrida en el norte español hasta el momento. Es muy probable que esas milicias pasaran por Fuenmayor y que los elementos absolutistas reaccionasen de esa manera ${ }^{52}$.

\section{Recibir al héroe: Riego en tierras riojanas}

El paso de Rafael del Riego por La Rioja camino de Zaragoza no podía quedar al margen de las celebraciones liberales. Así, además de los recibimientos y alojamientos ofrecidos y costeados por las autoridades locales, la ciudadanía más cercana al liberalismo no perdió la ocasión de homenajear públicamente al héroe. Sin duda alguna los menos afines también saldrían a ver, aunque solo fuese por curiosidad, a quien se había convertido en un mito.

A pesar de la participación de varios militares en la preparación del levantamiento constitucional del 1 de enero de 1820, entre los que destacaron Quiroga, Arco-Agüero, López Baños y O’Daly, fue Rafael del Riego quien consiguió elevarse desde el primer momento en el líder preclaro del constitucionalismo restaurado $^{53}$. Y su halo de fama se extendió y se acrecentó con el paso de los meses. Su heroica acción no concluida hasta el 11 de marzo, su firme determinación a pesar de las dudas iniciales, su compromiso con el liberalismo du-

50. AML, Libro de acuerdos de 1819-1820, sesión de 22 de abril de 1820.

51. AML, Libro de acuerdos de 1819-1820, sesiones de 27 de mayo y 3 de junio de 1820.

52. AHPLR, Judicial, 211/8.

53. A día de hoy, la mejor investigación realizada sobre Rafael del Riego ha corrido a cargo de Sánchez Martín, V., Rafael del Riego... 
rante todo el Trienio y su empeño en el triunfo liberal a pesar de su división, lo elevaron a lo más alto del altar de las libertades. La lectura de un manifiesto el 1 de enero lo convirtió en protagonista e icono de ese crucial momento, y los españoles, tanto los liberales como los absolutistas, le atribuyeron el retorno al constitucionalismo ${ }^{54}$. Pronto fraguó el mito. Con el triunfo de la revolución se abrió un proceso de heroización y lo hizo de forma casi inmediata con gestos como su pertinaz negativa a aceptar un ascenso inmediato al generalato, lo que le separó de los demás militares revolucionarios que sí aceptaron, si bien finalmente accedió ${ }^{55}$. En apenas unas semanas pasó de ser un militar a punto de embarcar para América, a convertirse en emblema de la revolución liberal, un símbolo que ha perdurado hasta la actualidad ${ }^{56}$. En su nombre se hicieron proclamas, se fundaron sociedades patrióticas, se cantó la marcha que habían entonado sus hombres durante el pronunciamiento, se sacó su retrato en procesión, se imprimieron grabados conmemorativos, y se escribieron odas, poemas y obras teatrales ${ }^{57}$.

El 2 de agosto Fernando VII nombró a Riego capitán general de Galicia en respuesta a la disolución del Ejército de la Isla. Riego Ilegó a Madrid el 30 de agosto, siendo recibido con multitudinarias aclamaciones populares ${ }^{58}$. Días después, el 3 de septiembre, se produjo el incidente que fue usado para desacreditarle ante la opinión pública al atribuirle el canto del 'Trágala' contra el rey en un teatro madrileño ${ }^{59}$. Una de las funestas consecuencias fue la designación de un nuevo destino para Riego, Oviedo, y las acusaciones de republicanismo vertidas contra él en las Cortes ${ }^{60}$. Todo esto contribuyó a afianzar su imagen entre los liberales exaltados. Tras la necesidad de Fernando VII de rectificar el nombramiento unilateral de José de Carvajal como capitán general de Castilla la Nueva, el 28 de noviembre nombró a Riego capitán general de Aragón ${ }^{61}$.

En su camino hacia Zaragoza Riego pasó por La Rioja. Los liberales riojanos le recibieron en los caminos y en las calles de las localidades por las que transitó. El 1 de enero de 1821 Ilegó a Haro, el día 2 fue recibido en Logroño, donde permaneció hasta el día 4, esa noche durmió en Calahorra y el día 5 salió para Tudela. En La Rioja disfrutó de una multitudinaria adhesión. Precisamente uno

54. La Parra, E., Los Cien mil hijos de San Luis. El ocaso del primer impulso liberal en España, Madrid, Síntesis, 2007, p. 241.

55. Sánchez Martín, V., Rafael del Riego..., p. 364.

56. Fuentes, J. F., "Yo nada valgo: Rafael del Riego y la revolución liberal española", en Pérez Ledesma, M. y Burdiel, I. (eds.), Liberales eminentes, Madrid, Marcial Pons, 2008, p. 16.

57. Ibídem, pp. 13-14 y 28; Sánchez Martín, V., Rafael del Riego..., p. 416.

58. El Constitucional: o sea crónica científica, literaria y política, núm. 481, viernes 1 de septiembre de 1820, p. 1; El Universal, núm. 113, viernes 1 de septiembre de 1820, p. 418, núm. 114, sábado 2 de septiembre de 1820, p. 421.

59. Sánchez Martín, V., Rafael del Riego..., pp. 464-465 y 470.

60. Diario de sesiones de Cortes (DSC), sesión de 7 de septiembre de 1820, p. 860.

61. Sánchez Martín, V., Rafael del Riego..., p. 511. 
de los personajes que salió al encuentro fue el mencionado cura de Navarrete Antonio Mendizábal y Llorente ${ }^{62}$.

En Haro salió a buscarle a la carretera un gran gentío. Le recibió el batallón de la Milicia Nacional, el ayuntamiento y el cabildo eclesiástico. Se le ofreció una comida presidida por el alcalde y con presencia de todas las autoridades; durante la misma las calles estaban intransitables por la cantidad de gente que vitoreaba al general, el cual se asomó al balcón y dijo algunas palabras. Pasó allí la noche y a la mañana siguiente a las seis salió para Logroño, pasando antes por las localidades de Cenicero y Fuenmayor ${ }^{63}$.

En Logroño se produjeron grandes manifestaciones públicas. Para recibirle se tiraron cohetes y bombas, y salió la caballería para acompañarle a modo de gran procesión cívica. Se levantó un arco de hiedra en el puente de las FontaniIlas, extramuros de la ciudad, donde se le esperó con música. Se hizo un segundo arco en la puerta del Carmen, por donde accedió a la ciudad, y un tercero en la casa de Juan Cesáreo Tejada, donde se alojó y se le recibió con más música. Todo se acompañó con repique de campanas ${ }^{64}$. Hubo también un baile público en la calle de la casa del Marqués de Monesterio y se limpiaron las calles. Se aprobó el encendido de la iluminación nocturna de siete a nueve de la noche y la colocación de colgaduras en los balcones desde la puerta del Carmen hasta la colegiata de Santa María de la Redonda, en la calle Mercaderes, y por los Cuatro Cantones hasta la casa de Tejada ${ }^{65}$. El pueblo quiso arrastrar la carroza en la que fue recibido al son de "su himno", a lo que Riego se negó. Las crónicas periodísticas destacaron el ambiente constitucional de la ciudad "que si todos los pueblos de España estuvieran animados del mismo entusiasmo que reina en Logroño, serían vanos los esfuerzos de todos los perversos"66.

Riego llegó a Calahorra el día 4 y allí durmió. En esta ciudad el ayuntamiento se gastó 3.000 reales en los agasajos, y otros 3.000 para el alojamiento de su tropa $^{67}$. Al día siguiente partió de La Rioja en dirección a la ciudad navarra de Tudela $^{68}$. En Aldeanueva de Ebro salió a recibirlo a caballo y vestido de corto otro eclesiástico del que también se ha hablado, Román de Lerena, cura párroco de la localidad ${ }^{69}$.

62. Montoya, P. de, La intervención del clero vasco en las contiendas civiles. 1820-1823, San Sebastián, Txertoa, 1971, pp. 278-281.

63. Hergueta Martín, D., Noticias históricas de la muy noble y muy leal ciudad de Haro, Imprenta Sáenz-López, Haro, 1906, p. 545.

64. AML, Libro de acuerdos de 1819-1820, sesión de 26 de diciembre de 1820.

65. AML, Libro de acuerdos de 1819-1820, sesiones de 29 y 30 de diciembre de 1820 y AML, Libro de acuerdos de 1821, sesiones de 1 y 9 de enero.

66. El Universal 19, viernes 19 de enero de 1821, p. 70.

67. Cañas Díez, S., Crisis del Antiguo Régimen..., p. 459.

68. Miscelánea de comercio, política y literatura 325, jueves 18 de enero de 1821, p. 2.

69. ADC, leg. 27/843-86 (1823-VII-14). 
Al abrigo de las recobradas libertades, el liberalismo fue convirtiendo poco a poco el espacio público en un escenario idóneo en el que mostrar no solo la llegada de un nuevo tiempo, sino también para homenajear a sus protagonistas y resaltar los distintos hitos políticos que se iban sucediendo. De igual manera los absolutistas, con un significado contrario, y conscientes de su fuerza ideológica, continuaron respondiendo en la calle a las manifestaciones y exaltaciones públicas de los liberales.

Mientras Riego estuvo en La Rioja los realistas no se hicieron notar debido a la notable presencia militar. Sin embargo, unos días después respondieron en Logroño a los homenajes a Riego no con proclamas o escritos, sino atacando nuevamente al más visible y público símbolo constitucional, la lápida de la Constitución. El 6 de enero apareció ensuciada una de las dos lápidas que se habían colocado en sendas torres de la colegiata. La respuesta liberal fue igualmente pública y al día siguiente se celebró un ayuntamiento extraordinario y se ordenó la conformación de una guardia militar que velase por la integridad de la placa ${ }^{70}$. La limpieza de la lápida se convirtió en un nuevo acto de exaltación liberal y los dos alcaldes de la ciudad, Ambrosio Aranguren y Pedro Nolasco Albo, la limpiaron personalmente en presencia del ayuntamiento y de un gran gentío que salía de la función religiosa de Santa María de la Redonda. Fue un signo público destinado a evidenciar el compromiso constitucional de la institución municipal y de la ciudadanía. El acto estuvo acompañado por una alocución del alcalde Ambrosio Aranguren en la que reprendió "al vil que osó con sacrílega mano tiznar el nombre de nuestra lograda Constitución". También ofreció un premio a quien averiguase el nombre del sujeto que había cometido el atentado. Era evidente que la reacción absolutista se había realizado como respuesta a la estancia de Riego, pues además señaló que, a pesar de este hecho, el general había comprobado los nobles sentimientos constitucionales de los ciudadanos logroñeses, habiendo dado las gracias por el recibimiento ${ }^{71}$. Todo iría acompañado por distintos vivas y otras arengas ${ }^{72}$.

\section{5. 'Comidas patrióticas': fiesta y celebración en torno a la mesa}

Una de las manifestaciones públicas más singulares de este primer liberalismo fueron las comidas populares, denominadas habitualmente como 'comidas patrióticas' con la evidente intención de destacar su clara significación política. Se celebraron por todo el país y a lo largo de todo el Trienio, siendo varias

70. AML, Libro de acuerdos de 1821, sesión de 7 de enero.

71. Diario mercantil de Cádiz 1625, miércoles 17 de enero de 1821, p. 2. Se indica que Riego dijo sobre la ciudad que "no hay en la Nación un pueblo tan constitucional como Logroño".

72. AML, Libro de acuerdos de 1821, sesión de 7 de enero. 
las razones de su convocatoria ${ }^{73}$. Lo mismo sirvieron para agasajar a un héroe como Quiroga el 23 de junio de 1820 en Madrid, que para festejar en la misma capital el triunfo contra los absolutistas tras los sucesos del 7 de julio de $1822^{74}$.

En La Rioja, la primera de la que se tiene constancia se organizó con motivo de la intervención de las tropas de la ciudad, incluida su Milicia Nacional, en las acciones militares contra los absolutistas de Salvatierra en abril de 1821, si bien se desconoce cuándo y dónde se llevó a cabo ${ }^{75}$. Más información se tiene sobre la celebrada el 23 de septiembre de ese mismo año con motivo de la apertura de las sesiones extraordinarias de las Cortes, las cuales habían tenido su primera sesión preparatoria el día anterior. Se convocó a la población a una comida patriótica en el paseo del Espolón pagada por el ayuntamiento. Debió participar una considerable masa de gente a juzgar por los 1.980 reales y 6 maravedíes que costó ${ }^{76}$. De ella se dio noticia días después en el periódico exaltado y comunero de Madrid El Eco de Padilla, el cual afirmó que la asistencia al acto llegó a los 600 comensales, resaltando la gran fiesta constitucional que se organizó ${ }^{77}$.

La descripción del banquete fue detallada en dicha carta, la cual se reproduce a continuación por su gran interés:

Logroño 24 de septiembre.

Amigos míos: mientras en esa capital se cierran las Fontanas de Oro, se da al traste con sus oradores, y se hacen otras habilidades de esta especie cuyo recuerdo me pone de mal humor, aquí damos al espíritu público un impulso admirable. Ayer tuvimos un banquete al que asistieron de riguroso uniforme individuos de la Milicia Local, de las provincias, regimiento de Jaén, resguardo militar, eclesiásticos seculares y regulares, dependientes de la hacienda nacional, y otra porción de ciudadanos hasta el número de 600 cubiertos. En el Espolón, donde fue la comida, se colocó una pirámide en cuya cúspide había un genio que representaba la España con un lema en la mano que decía: Cortes extraordinarias. En los ángulos del Espolón había dos planchas donde se leía "amistad pura: unión perfecta". Después de concluida la comida, y de dar muchos vivas a la nación, al código de nuestros derechos y a los que tan valientemente nos lo restituyeron, marchamos por las calles precedidos de una gran orquesta. Nos acompañaban todos los militares en una perfecta formación, componiendo entre todos una columna de más de 400

73. Fuentes Aragonés, J. F., "La fiesta revolucionaria...", p. 51.

74. Lécuyer, M. C., "Fêtes civiques et libéralisme...", pp. 60-61.

75. AML, Libro de acuerdos de 1821, sesión de 29 de septiembre.

76. AML, Libro de acuerdos de 1821, sesión de 2 de octubre.

77. El Eco de Padilla 60, sábado 29 de septiembre de 1821, p. 2. 
hombres. Delante de la lápida arengó enérgicamente el comandante de las armas y se repitieron con indecible entusiasmo los vivas y aclamaciones. Seguimos la carrera hasta terminarla otra vez en el Espolón donde estaban todas las damas de la ciudad y muchas de los pueblos inmediatos y se bailó largamente. Hubo grande armonía, mucha unión y extraordinaria paz y tranquilidad. Es preciso confesar que Logroño es uno de los pueblos más constitucionales de la tierra. Debe llamarse la ciudad sagrada \&c. $=$ Carta particular ${ }^{78}$.

El director del ceremonial fue el militar Andrés Eguaguirre, que era el comandante de armas y autoridad militar máxima de la ciudad. Se trató de un liberal exaltado integrado inicialmente en la Sociedad Patriótica de Logroño y posteriormente en la sociedad secreta de los comuneros, por lo que no parece extraño que fuese él mismo quien redactase la nota y la enviase a El ECO de Padilla, periódico afín por ser entonces el medio de expresión de la comunería ${ }^{79}$.

Debe ser destacada la excepcional escenografía efímera que se montó, la cual fue ejemplo de una nueva sensibilidad. Así, en la breve narración se informó de la elevación de una pirámide coronada por un "genio" que representaba a la nación y que sujetaba un lema alusivo a las Cortes. Además, en sendos extremos del paseo del Espolón se colocaron dos carteles. Todo parece indicar que en uno rezaba la expresión "Amistad pura" y en otro "Unión perfecta". Butrón Prida ya incidió en el gusto que se despertó en el Trienio por la geometría, y en definitiva por crear en este tipo de actos públicos unas escenografías bellas, simples y equilibradas, recordándose con ello el deber de recobrar la plenitud y simplicidad de su naturaleza. Se añadieron imágenes a las ideas, construyéndose monumentos efímeros con alegorías y emblemas influidos por una figuración creada en la Revolución francesa y adoptada plenamente. Todo ello ligado además al neoclasicismo artístico. Por ejemplo, en el Cádiz de 1821 se elevó en la plaza de la Constitución un obelisco con base circular buscándose con ello la verticalidad y la mirada del hombre hacia el cielo ${ }^{80}$. En el caso de Logroño esa mirada culminaría en el mencionado "genio" que presidió el banquete, y en el texto de homenaje a las Cortes.

Finalmente, hay noticia de que el domingo 3 de marzo de 1822 la Milicia Nacional de Logroño organizó otra "comida patriótica" con motivo del inicio de las sesiones de la legislatura ordinaria, la cual se había abierto el 1 de marzo. En este caso se convocó en el conocido como "sitio del Chibero" y se desconocen más detalles sobre su celebración ${ }^{81}$.

78. Ibídem.

79. Bustos, S., La nación no es patrimonio de nadie. El liberalismo exaltado en el Madrid del Trienio Liberal (1820-1823): Cortes. Gobierno y opinión pública, tesis doctoral, Universidad Autónoma de Madrid, 2017, p. 56.

80. Butrón Prida, G., "Fiesta y revolución...", pp. 161 y 166.

81. AML, Libro de acuerdos de 1822, sesión de 1 de marzo. 


\section{Otros actos públicos}

La fundación y apertura de las reuniones de la Sociedad Patriótica de Logroño el 12 de abril de 1820 también llevó a la celebración de actos de homenaje y exaltación del sistema constitucional. En este caso no se produjeron en el espacio público urbano, sino en el Café Nacional de la ciudad, si bien la trascendencia que tuvieron, provocaron en las calles una extraordinaria presencia de liberales ${ }^{82}$. Como respuesta, los absolutistas sí utilizaron las vías públicas para manifestar su clara oposición a este nuevo tiempo, y en concreto a la fundación de señalada sociedad patriótica. Así, el 23 de abril aparecieron varios pasquines contrarios a dicha sociedad en las calles más concurridas de la ciudad ${ }^{83}$.

Por otro lado, uno de los actos con mayor significación en los inicios del Trienio fue la eliminación de los denominados signos de vasallaje ubicados en el espacio público. Con ello se quería poner de manifiesto de forma explícita la supresión de fueros y privilegios indicada en la Constitución, y en concreto la de una de las instituciones más arraigadas del absolutismo, los señoríos, Ilevada a cabo por el polémico y controvertido decreto de 6 de agosto de 1811. En Logroño fue el 13 de mayo de 1820 cuando se aprobó suprimir esos símbolos señoriales, y atendía a un decreto previo de 13 de abril de la Junta provisional que instaba a la demolición de los mismos ${ }^{84}$. En concreto, en esta ciudad se procedió a la retirada de las cadenas señoriales ubicadas en las fachadas de la iglesia de Santa María de Palacio y del convento de Madre de Dios, así como las colocadas en las casas de Juan Bautista Gamarra y Francisco Salazar, las cuales unían tres pilares situados en medio de la plazuela conocida precisamente como 'de la Cadena' 85 .

El liberalismo riojano del Trienio también recordó públicamente el '2 de mayo' madrileño, convertido ya en gesta de carácter nacional ${ }^{86}$. Se trato de una fiesta de naturaleza conmemorativa ${ }^{87}$, si bien las circunstancias bélicas que en algunos casos se vivieron en La Rioja no permitieron un recuerdo anual del hecho, no obstante se observa que fue un hito ineludible. El homenaje público se ciñó a la celebración de una misa de Te Deum, pues no consta la organización de otro tipo de acto o fiesta. En Santo Domingo de la Calzada el 2 de mayo de 1820 se conmemoró con una misa celebrada en la catedral en cumplimiento

82. El detalle de todo ello en: Díez Morrás, F. J., "La antorcha de la libertad resplandece"..., pp. 67 y ss.

83. Ibídem, p. 74.

84. AML, Libro de acuerdos de 1819-1820, sesión de 13 de mayo de 1820.

85. Díez Morrás, F. J., "La antorcha de la libertad resplandece"..., pp. 133-135.

86. Sobre la celebración del 2 de mayo por los liberales a partir de 1809: Butrón Prida, G., "Fiesta y revolución...", pp. 169-172.

87. Lécuyer, M. C., "Fêtes civiques et libéralisme...", p. 56. 
de una orden de las Cortes ${ }^{88}$, pero resulta especialmente significativo lo ocurrido en 1823. El 7 de abril ya estaban las tropas francesas en España ocupando el territorio, y para finales de mes habían tomado La Rioja deponiendo a las autoridades constitucionales. El cabildo catedralicio aprobó celebrar el 2 de mayo, pero solo si se la gesta se había celebrado antes de 1820, con lo que se observa que los eclesiásticos de la ciudad concebían esta celebración como una fiesta de naturaleza u origen liberal ${ }^{89}$. En la otra ciudad episcopal riojana, Calahorra, es posible que se celebrase desde 1820, habiendo constancia de que sí se hizo en $1821^{90}$.

\section{La lucha política en el nomenclátor callejero: de la plaza de la Constitu- ción a la plaza Real}

Se han observado distintas reacciones públicas del absolutismo riojano ante la celebración de actos y homenajes liberales. Con esos antecedentes, la toma del poder en La Rioja por aquellos tras la ocupación de Logroño por los franceses el 18 de abril de 1823, no podía quedar sin una réplica simbólica de significado anticonstitucional. Los realistas logroñeses habían comprobado que el uso del espacio público por parte del liberalismo había sido un método fundamental de instrucción popular y propaganda. Así, los absolutistas no desdeñaron esos mismos medios, con lo que el nuevo poder hizo también un uso manifiesto de ese espacio con idéntica intención política. La Junta provisional de gobierno de España e Indias, que había sido constituida nada más entrar los franceses en España, decretó en Burgos el 8 de mayo de 1823 que se eliminasen las lápidas de la Constitución de todas las localidades españolas y que en su lugar se colocasen otras con el nombre de plaza Rea ${ }^{91}$. La materialización de este cambio dio lugar a unas nuevas liturgias no menos ostensibles que las liberales. Es muy interesante apuntar la evidente intencionalidad ideológica de la orden de la Junta, pues esta no llevó a la recuperación de los tradicionales nombres de las plazas españolas previos a la jura de la Constitución -en los casos riojanos de Logroño y Santo Domingo de la Calzada, 'plaza del Mercado'- sino que con un ánimo de revancha y denigración, se optó por atribuirlas un nuevo nombre lleno de significado, el de plaza Real, en un claro homenaje y reivindicación de la soberanía del rey absolutista como única válida y reconocida. Se puede afirmar que con esta decisión se quería replicar al decreto de 1812 que había ordenado nombrar a las plazas juraderas como plaza de la Constitución.

88. Archivo catedral de Santo Domingo de la Calzada (ACSDC), Libro de actas de 1820, cabildo de 1 de mayo.

89. ACSDC, Libro de actas de 1823, cabildo de 26 de abril.

90. Cañas Díez, S., Crisis del Antiguo Régimen..., p. 461.

91. Circulares de la Junta provisional de gobierno, de España e Indias, Madrid, Imprenta Real, 1823, p. 31. 
Un claro ejemplo es lo ocurrido en la ciudad de Logroño, donde se venía experimentando una verdadera batalla pública por los símbolos desde la primera proclamación constitucional de 1813. El 26 de julio de 1823 el ayuntamiento aprobó el cambio del nombre de la plaza de la Constitución por el de plaza Real, de acuerdo con la citada orden llegada desde la Junta provisional dada en Burgos, sustituyendo la lápida. Pero no solo quedó en eso, porque el 9 de agosto se tomó la decisión de monumentalizar la nueva placa que iba a nombrar la plaza al aprobarse la construcción con decencia y lujo de una pirámide en la que se debía inscribir el nuevo nombre. La anterior lápida constitucional iba a ser sustituida por un elemento más ostentoso y visible con un evidente ánimo de destacar sobremanera el inicio de un nuevo tiempo, aunque aún no había sido formalmente derogada la Constitución ${ }^{92}$. A pesar de ser muy parca la descripción del monumento, es inevitable recordar la pirámide que los liberales logroñeses erigieron en el Espolón en el banquete ya señalado del 23 de septiembre de 1821 . Es posible que los absolutistas se acordasen de aquel efímero monumento liberal y quisiesen hacer también un uso político del mismo símbolo.

A pesar de todo, el monumento tardó en ser colocado. Pasó el tiempo y el 30 de agosto aún estaba pendiente la obra ${ }^{93}$. Finalmente el 13 de septiembre Manuel Celaya, profesor de cantería, presentó una cuenta por los gastos que había tenido hasta el momento por la realización de la pirámide, ascendiendo a 2.299 reales ${ }^{94}$. Pero a finales de septiembre no se había colocado aún, pues se solicitó al obispo la reubicación de la fuente situada en el espacio que fue jardín de la residencia del obispo, para en su lugar colocar el nuevo monumento ${ }^{95}$. No sé llevó a cabo, y para evitar más dilaciones, el 11 de octubre, diez días después de la derogación constitucional, se acordó finalmente no instalar la pirámide en el lugar previsto, sino fuera del terreno que perteneció al palacio episcopal. Ese mismo día se aprobó entregar a Salvador Funes 1.000 reales a cuenta del importe de la construcción del león de piedra que iba a colocarse en el monumento, quizás en su base ${ }^{96}$. El 16 de diciembre parece que la obra estaba concluida, pues se acordó pagar los jornales de su construcción, los cuales sumaban un importe de 3.807 reales. Cuatro días después aún hubo más pagos por distintos trabajos, en concreto a Manuel Zavala se le abonaron 77 reales atrasados, y 460 a Baltasar San Román. A Salvador Funes, por el tallado del león, se le volvieron a pagar 3.000 reales $^{97}$. A juzgar por el monto de todos los pagos, se debió tratar de un monumento de notable tamaño y calidad.

92. AML, Libro de acuerdos de 1823, sesiones de 26 de julio.

93. AML, Libro de acuerdos de 1823, sesiones de 2, 9 y 30 de agosto.

94. AML, Libro de acuerdos de 1823, sesión de 13 de septiembre.

95. AML, Libro de acuerdos de 1823, sesión de 27 de septiembre.

96. AML, Libro de acuerdos de 1823, sesión de 11 de octubre.

97. AML, Libro de acuerdos de 1823, sesiones de 16 y 20 de diciembre. 
El ocaso del período constitucional se certificó en Logroño de manera especialmente simbólica escribiendo el 13 de septiembre de 1823 una nota denigratoria sobre Rafael del Riego en el libro de actas de 1820, al margen del acuerdo en el que constaban los agasajos previstos durante su estancia. Su inscripción fue ordenada directamente por el corregidor Luis de Lemos ${ }^{98}$. La nota, con una rotunda carga ideológica en la que se destacó una supuesta irreligiosidad, republicanismo e inhumanidad de Riego, reza lo siguiente:

Por auto del Señor Corregidor de 23 de septiembre de 1823 se manda poner aquí la siguiente nota: Rafael Riego enemigo de la Religión de Jesucristo nuestro Dios verdadero, de los Reyes, y del género humano, ha sido indigno de semejante obsequio; los que lo han autorizado, y ejecutado, han sido castigados ${ }^{99}$

El 4 de octubre, tres días después de la derogación de la Constitución, se celebró un Te Deum de acción de gracias en la colegiata de Santa María de la Redonda por la "libertad plena de nuestro augusto Soberano" ${ }^{100}$. La Iglesia, siempre atenta a las demandas Ilegadas desde el poder político, fuese desde un lado o desde el otro, se sumaba a la denigración pública del sistema constitucional.

\section{Conclusiones}

El principal símbolo del primer liberalismo español fue la Constitución de 1812. La enseñanza y difusión de su articulado a través de sermones y 'catecismos' fue esencial para el afianzamiento del liberalismo, pues la mayoría de la ciudadanía desconocía los términos de su contenido, y la gran trascendencia de sus novedades y reformas. Para contribuir a ello se buscó además ofrecer una imagen icónica de la misma, y espacios públicos como las calles y las plazas fueron un ámbito propicio para lograrlo. Así, se decretó que la jura y promulgación constitucional se hiciese solemnemente en todas las plazas mayores de las localidades españolas, y en La Rioja también se llevó a cabo de la misma manera. Su finalidad fue propagandística, pero además se pretendió hacer partícipe a toda la ciudadanía de la llegada de un nuevo tiempo. Es posible afirmar que con ello las plazas juraderas se transformaron en una suerte de templos abiertos de la libertad, y en ellas el altar civil no sería otro que la lápida en la que quedó grabado el nuevo nombre de dichos espacios.

98. AML, Libro de acuerdos de 1823, sesión de 13 de septiembre. Durante la visita del general Riego, hizo lo posible por no asistir a los actos previstos, Díez Morrás, F. J., "La antorcha de la libertad resplandece"..., pp. 143-144.

99. AML, Libro de acuerdos de 1820, sesión de 26 de diciembre. Nota al margen.

100. AML, Libro de acuerdos de 1823, sesión de 4 de octubre. 
Porque si algo contribuyó durante el Trienio Liberal a mantener una permanente memoria constitucional en la ciudadanía, fue la obligatoriedad de renombrar las plazas públicas en las que se proclamó la Constitución y colocar en ellas una lápida con su nombre. Esta adquirió para los liberales un significado cuasi religioso, y el ejemplo más evidente es el empeño con el que los absolutistas mancillaron o destrozaron las lápidas erigiéndose en la diana perfecta en la que manifestar su desagrado con el sistema político liberal. Ejemplo de ello es la obsesión de los realistas por su eliminación y sustitución una vez retornado el absolutismo en 1823.

Por tanto, el decreto de 14 de agosto de 1812 que cambió el nombre de las plazas en las que se juró y proclamó la Constitución, y la orden de la absolutista Junta provisional de gobierno de 8 de mayo de 1823 que obligó a la eliminación de las lápidas constitucionales, y su sustitución por otras en las que constase el nombre de 'Plaza Real', abrieron en España la lucha por la nomenclatura del espacio público y su definitivo uso político. Porque el absolutismo no optó por devolver a dichas plazas juraderas sus nombres históricos anteriores al período liberal, sino que respondió utilizando una misma estrategia propagandística al darlas un nuevo nombre con especial significación, como ocurrió en Logroño. Con ello se inició una larga y polémica batalla por los nombres de las calles y plazas que continúa abierta y firme en el presente siglo XXI.

A la colocación de la lápida y sus honras se fueron sumando a lo largo del Trienio Liberal riojano otras manifestaciones políticas. Varias fueron organizadas por las autoridades como consecuencia de acontecimientos sobrevenidos y de distinta naturaleza, pero en otros, como en el caso de los banquetes patrióticos, se evidencia un protagonismo popular también en su convocatoria, alejándose por tanto de lo institucional. No obstante, eso no implicó improvisación o falta de compromiso, y de acuerdo con la documentación conservada, estas comidas populares, con evidentes reminiscencias en las romerías religiosas, fueron muy concurridas y estuvieron convenientemente adornadas con significativos símbolos. Se observa entre los liberales riojanos un deseo de confraternización, erigiéndose en actos de reafirmación liberal participados por distintos estratos sociales.

En otros momentos el uso del espacio público se hizo como respuesta inmediata a la actividad absolutista o a la recepción de buenas noticias. Sería el caso tanto de las reacciones ante los atentados contra los símbolos constitucionales, como ante la Ilegada a La Rioja del general Riego. Aunque todos los señalados son de diferente naturaleza, hay que resaltar que en ellos se hizo un uso libre y muy destacado del espacio público urbano. El presente trabajo ha permitido acercarnos a los tipos sociales que protagonizaron o participaron en los distintos actos. Se observa la presencia casi constante de una heterogénea ciudadanía en ceremonias vinculadas a la proclamación constitucional, o en los oficios religiosos; también se aprecia el compromiso de parte del cuerpo 
eclesiástico más cercano al constitucionalismo; de sectores militares; y de las familias liberales, entre ellas los exaltados, celebrando por ejemplo banquetes patrióticos, o persiguiendo a los que atentaron contra los símbolos del nuevo Estado.

Finalmente hay que destacar una naturaleza mixta cívico-religiosa en buena parte de las fiestas políticas liberales riojanas, pues permanecieron en ellas unos ceremoniales firmemente arraigados en la sociedad del antiguo régimen, como los procesionados o las liturgias religiosas, principalmente las misas y los Te Deums. Por otra parte, las escenografías montadas en marzo de 1820 con motivo de la proclamación constitucional, recuerdan a aquellas que se colocaban en ciudades principales con motivo de los actos organizados en los esponsales regios, nacimientos de infantes o coronaciones. Se aprecia también el interés de las autoridades municipales -no menos religiosas que el resto de la ciudadanía- por ganarse al clero y al pueblo escéptico, pero también su deseo de defender la irrenunciable catolicidad del sistema liberal. Todo ello sirvió de escenario para la autoafirmación de una ciudadanía afín o cercana al liberalismo, pero también debe verse como el intento por consolidar una posición de fuerza ante la creciente desconfianza en el sistema, y frente al absolutismo de muchos y del mismo rey. El ejemplo está en que, nada más producirse la derrota del constitucionalismo en La Rioja, el realismo utilizó el mismo espacio público urbano para abrir otra era de propaganda, en este caso de signo político contrario.

\section{Fuentes}

Archivo Diocesano de Calahorra

Archivo Histórico Provincial de La Rioja. Judicial

Archivo Municipal de Logroño, Libros de acuerdos de 1820, 1821, 1822 y 1823

Archivo Municipal de Santo Domingo de la Calzada

Archivo Municipal de Haro

Biblioteca de La Rioja. Fondo Antiguo

Diario de sesiones de Cortes, 1820

El Constitucional: o sea crónica científica, literaria y política, núm. 481, viernes 1 de septiembre de 1820

El Eco de Padilla 60, sábado 29 de septiembre de 1821

El Universal 113, viernes 1 de septiembre de 1820

El Universal 114, sábado 2 de septiembre de 1820

El Universal 19, viernes 19 de enero de 1821

Miscelánea de comercio, política y literatura 325, jueves 18 de enero de 1821 


\section{Bibliografía}

Arnabat, R., "Propaganda antiliberal i Iluita ideológica durant el Trieni Liberal a Catalunya (1820-1823)", Recerques: Història, economia i cultura 34 (1996), pp. 7-28.

Arnabat, R., "La divulgación popular de la cultura liberal durante el Trienio: Cataluña, 1820-1823", Trienio: Ilustración y liberalismo 41 (2003), pp. 55-83.

Bustos, S., La nación no es patrimonio de nadie. El liberalismo exaltado en el Madrid del Trienio Liberal (1820-1823): Cortes. Gobierno y opinión pública, tesis doctoral, Universidad Autónoma de Madrid, 2017.

Butrón Prida, G., "Fiesta revolucionaria en el Cádiz constitucional", en Antiguo Régimen y liberalismo. Homenaje a Miguel Artola, vol. 3, Madrid, Alianza Editorial, Universidad Autónoma de Madrid, 1995, pp. 439-444.

Butrón Prida, G., "La fiesta y revolución: las celebraciones políticas en el Cádiz liberal (1812-1837)", en Gil Novales, A. (coord.), La revolución liberal, Ediciones del Orto, 2001, pp. 159-178.

Cañas Díez, S., Crisis del Antiguo Régimen y liberalismo en Calahorra (La Rioja) 1788-1840, tesis doctoral, Universidad de La Rioja, 2016.

Circulares de la Junta provisional de gobierno, de España e Indias, Madrid, Imprenta Real, 1823.

Colección de los decretos y órdenes que han expedido las Cortes generales y extraordinarias, desde 24 de septiembre de 1811 hasta 24 de mayo de 1812, tomo II, Cádiz, Imprenta Nacional, 1820.

Colección de los decretos y órdenes que han expedido las Cortes generales y extraordinarias, desde 24 de mayo de 1812 hasta 24 de febrero de 1813, tomo III, Cádiz, Imprenta Nacional, 1820.

Díez Morrás, F. J., "Tiempo de cambios: Santo Domingo de la Calzada entre el Antiguo Régimen y el primer liberalismo", en Díez Morrás, F. J., Fandiño Pérez, R. G. y Sáez Miguel, P., Historia de la ciudad de Santo Domingo de la Calzada, Logroño, Instituto de Estudios Riojanos, 2010, pp. 387-504.

Díez Morrás, F. J., "La antorcha de la libertad resplandece". La Sociedad patriótica de Logroño y los inicios del liberalismo, Logroño, Instituto de Estudios Riojanos, 2016.

Díez Morrás, F. J., "Román de Lerena, el cura que salió a recibir a Riego", Piedra de Rayo 52 (2018), pp. 60-69.

Fabra, P., Habermas: lenguaje, razón y verdad. Los fundamentos del cognitivismo en Jürgen Habermas, Madrid, Marcial Pons, 2008.

Fernández Sarasola, I., Los partidos políticos en el pensamiento español. De la Ilustración a nuestros días, Madrid, Marcial Pons, 2009. 
Forcadell Álvarez, C., "Usos públicos de mitos, representaciones y símbolos en el primer liberalismo", Jerónimo Zurita 88 (2013), pp. 259-274.

Fuentes Aragonés, J. F., "Yo nada valgo: Rafael del Riego y la revolución liberal española", en Pérez Ledesma, M. y Burdiel, I. (eds.), Liberales eminentes, Madrid, Marcial Pons, 2008, pp. 13-42.

Fuentes Aragonés, J. F., "La fiesta revolucionaria en el trienio liberal (18201823)", Historia social 78 (2014), pp. 43-59.

García León, J. M., Cádiz en el Trienio Liberal (1820-1823), Cádiz, Fundación Municipal de Cultura, 1999.

Gil Novales, A., El Trienio liberal, Madrid, Siglo XXI, 1980.

Gómez Urdáñez, J. L., Bustos Torres, S. y Espinosa de los Monteros, J. M., "El fin del Antiguo Régimen. Guerra, revolución y reacción en Haro", en Gómez Urdáñez, J. L. (dir.), Haro Histórico, Ayuntamiento de Haro, Universidad de La Rioja, 2017. Disponible en: http://www.gomezurdanez.com/haro/.

Hergueta Martín, D., Noticias históricas de la muy noble y muy leal ciudad de Haro, Imprenta Sáenz-López, Haro, 1906.

Habermas, J., Historia y crítica de la opinión pública. La transformación estructural de la vida pública, Barcelona, Gustavo Gili, 1982.

La Parra, E., El primer liberalismo y la Iglesia. Las Cortes de Cádiz, Alicante, Instituto de Estudios Juan Gil-Albert, 1985.

La Parra, E., Los Cien mil hijos de San Luis. El ocaso del primer impulso liberal en España, Madrid, Síntesis, 2007.

La Parra, E., Fernando VII. Un rey deseado y detestado, Barcelona, Tusquets, 2018

Lécuyer, M. C., "Fêtes civiques et libéralisme en Espagne (1812-1843)", Bulletin d'Histoire contemporaine de l'Espagne 30-31 (déc. 1999-jun. 2000), pp. 54-70.

López, R. J., "Entre la tradición y la modernidad. Las ceremonias públicas gaIlegas en el reinado de Fernando VII", Espacio, Tiempo y Forma, Serie IV, 10 (1997), pp. 375-403.

López González, J. L., El derecho de reunión y manifestación en el ordenamiento constitucional español, Madrid, Ministerio de Justicia e Interior, 1995.

Montoya, P. de, La intervención del clero vasco en las contiendas civiles. 18201823, San Sebastián, Txertoa, 1971.

Morales Muñoz, M., "Símbolos y lugares de la memoria en torno a la Constitución de 1812", TSN. Transatlantic Studies Network: Revista de Estudios Internacionales 3 (2017), pp. 141-157.

Reyero Hermosilla, C., Alegoría, nación y libertad. El Olimpo constitucional de 1812, Madrid, Siglo XXI, 2010.

Roca Vernet, J., "Fiestas cívicas en la revolución liberal: entusiasmo y popularidad del régimen", Historia Social 86 (2016), pp. 71-90. 
FRANCISCO JAVIER DÍEZ MORRÁS

Sánchez Martín, V., Rafael del Riego, símbolo de la revolución liberal, tesis doctoral, Universidad de Alicante, 2016.

Yamamichi, Y., "Fiestas y celebraciones cívico-religiosas en la Barcelona constitucional (1820-1823)", Espacio, Tiempo y Forma, Serie V, 15 (2002), pp. 123-155. 